\title{
EUS and ampullary adenoma: Why? When?
}

Authors

Institutions
María-Victoria Alvarez-Sánchez ${ }^{1,2}$, Bertrand Napoleon ${ }^{1}$

1 Department of Gastroenterology, Ramsay Générale de Santé, Private Hospital Jean Mermoz, Lyon, France

${ }^{2}$ Department of Gastroenterology, Complejo Hospitalario Universitario de Pontevedra, Pontevedra, Spain submitted: 22. April 2016 accepted after revision: 27. April 2016

\section{Bibliography}

Dol http://dx.doi.org/ 10.1055/s-0042-107790 Endoscopy International Open 2016; 04: E1319-E1321 (c) Georg Thieme Verlag KG Stuttgart · New York E-ISSN 2196-9736

Corresponding author Bertrand Napoleon Ramsay Générale de Santé, Private Hospital Jean Mermoz, Lyon, France

55 Avenue Mermoz Lyon 69008

France

dr.napoleon@wanadoo.fr
The ampullary region is a highly complex anatomic area composed of the following histologically and functionally distinct structures: the ampullary common duct or ampulla, formed by the dilated confluence of the pancreatic and common bile duct; the sphincter of Oddi; and the duodenum with the papilla of Vater, where the ampulla opens into the duodenum [1]. Due to its complexity, this small anatomic area gives rise to a heterogeneous group of tumors with different biological behaviours and spreading patterns. Ampullary tumours, although relatively uncommon, are increasingly diagnosed due to advances in imaging technology, and their management approach remains controversial. For benign ampullary adenomas, endoscopic resection has become the preferred option over surgery given its lower morbidity. However, incomplete resection may result from spreading inside the bile or pancreatic duct. Moreover, whereas endoscopic resection may be curative for selected patients with early ampullary cancer confined to the mucosa, the risk of metastatic lymph nodes arises as soon as the carcinoma invades beyond the sphincter of Oddi. Preoperative assessment of tumor depth is therefore crucial in the process of deciding between surgery and endoscopic resection. Nevertheless, owing to the complex anatomic coalescence at the ampullary region, understanding the threedimensional spreading patterns of tumors arising here is difficult. Therefore, these tumors are probably the most challenging in terms of staging [2]. The close proximity of the ultrasound transducer to the duodenum during endoscopic ultrasonography (EUS) provides high-spatial-resolution images of the ampullary region and enables clear visualization of the duodenal wall layers. EUS has been shown to be superior to computed tomography or magnetic resonance imaging for assessment of tumor depth invasion and intraductal extension in ampullary tumours [3]. In addition, when compared with surgical specimens, EUS performs similarly to endoscopic retrograde cholangiography (ERCP) in evaluating intraductal extension but without the risk of complications inherent to ERCP [4]. Although radial and linear EUS equipment have comparable accuracy for assessment of intraductal invasion, in our experience, the image of the papilla is less defined with the linear equipment. However, no study has involved a direct comparison between linear and radial EUS for Tumor staging, and the choice of using these instruments depends mostly on the operator's preferences. Only intraductal ultrasonography (IDUS) has demonstrated superiority to EUS in terms of tumor visualization and staging [5]. IDUS allows differentiation between the duodenal wall layer and the sphincter of Oddi, but its limited ultrasound penetration prevents it from exploring possible lymph nodes, and it is not widely available.

EUS is now considered the modality of choice for local staging of ampullary tumors, but whether EUS should be performed in all patients with ampullary tumors is still uncertain, and some guidelines recommend EUS on a case-by-case basis [6]. This recommendation is based on expert opinions suggesting that EUS should be used only in ampullary tumours larger than $1 \mathrm{~cm}$ or with features suggesting malignancy; however, no evidence that supports this view is available at present [7]. In this month's issue of Endoscopy International Open, Patel et al. offer an original perspective on the topic of tumor size as a predictor of invasive stage by studying the relationship between tumor size and intraductal invasion [8]. A total of 120 patients with a benign ampullary tumor on endoscopic biopsies underwent EUS before endoscopic or surgical ampullectomy. Among them, 35 tumors had intraductal invasion on EUS and were significantly larger than those without invasion on EUS ( $22 \pm 12 \mathrm{~mm}$ vs $14 \pm 11 \mathrm{~mm}$, respectively, $P$ $>0.0001$ ). They found that a tumor size smaller than $5.5 \mathrm{~mm}$ had $100 \%$ sensitivity for absence of 
intraductal invasion in EUS, although with low specificity (13\%). This result is in agreement with previous expert opinions. Baillie recommended performing EUS only in cases where the ducts appear involved or if the lesion is larger than $1 \mathrm{~cm}$ to determine whether surgery should be performed [7]. However, as acknowledged by the authors, one important limitation in the study by Patel et al. is that the size was obtained from the pathology reports. It has been largely demonstrated that significant discordance exists between endoscopic and pathology-based assessments of polyp size without a clear correlation between them, and both endoscopic over- and underestimation have been described $[9,10]$. Moreover, it is not clear in the study's methods if the reported size refers to the whole resected ampullary specimen or to the adenoma in the specimen. Finally, although endoscopic measurement may be subjective, it is the only way to estimate size before endoscopic resection. Perhaps, a more objective way to assess size before a papillectomy would be EUS-based measurement. In line with the view that at larger sizes the risk of invasiveness is higher, in some studies that address early ampullary cancer, the authors have reported a significant correlation between tumor size and lymph node metastases (LNMs). This finding led Woo et al to suggest that only certain ampullary cancers smaller than $2 \mathrm{~cm}$ are suitable for endoscopic resection [11]. Lee et al retrospectively reviewed clinico-histologic data from 59 patients diagnosed with carcinoma of the ampulla of Vater after surgical ampullectomy. Large tumor size was positively correlated with LNMs; however, some small tumors were also associated with LNMs [12].

Actually, most studies in the literature have failed to show a significant association between tumor size and LNMs [13,14]. Other characteristics may be more important. Due to the transitional features of the epithelium lining the ampulla, between the intestinal and biliopancreatic epithelia, tumors arising in the ampullary region form a heterogeneous group of tumors with different histologic subtypes and biological behavior. Thus, in our own series of 28 patients with ampullary cancer (under submission) who underwent endoscopic papillectomy, tumor size was inversely related to LNM presence. After analyzing different subgroups, we found that the smaller cancers of the biliopancreatic subtype in our series may have accounted, in part, for this result. The biliopancreatic subtype showed $100 \%$ submucosal invasion and $71 \%$ LNMs. The worst prognosis for this subtype may be explained by the deeper origin of the tumors inside the ampulla, which enables them to spread easily into the ducts and the groove area at the posterior aspect of the ampulla [15]. In addition, our findings suggest that tumor size may not be an independent risk factor for invasive cancer.

As a second endpoint, Patel et al. address the issue of sensitivity and specificity of intraductal invasion on EUS for malignancy on histologic specimens. Although this is a retrospective study, one strength is the consistency of referral patterns for surgical or endoscopic treatment. The majority of patients with duct ingrowth underwent surgery, and thus, the authors demonstrate that intraductal invasion in EUS is highly specific for malignancy, high-grade dysplasia (HGD) and intraductal invasion on surgical specimens ( $97 \%$ specificity). This result prompted the authors to support surgical resection in cases with intraductal invasion; however, endoscopic papillectomy may be curative in ampullary adenomas with HGD and noninvasive adenocarcinoma provided that complete resection is achieved. In experienced centers, complete resection is satisfactorily performed when ductal ingrowth is limited to $1 \mathrm{~cm}$ [16]. Furthermore, new ablative treatments, such as radiofrequency, may assist in treatment of residual intraductal tumor after papillectomy $[17,18]$. Instead of evaluating the correlation between intraductal ingrowth and malignancy, it would have been more relevant to investigate a possible association between intraductal invasion and invasive ampullary cancer at risk of LMN, where surgery is the only curative modality of treatment. For this purpose, a multivariate analysis including morphologic and histologic features, duodenal wall invasion, and ductal ingrowth would be required.

Endoscopic papillectomy is now the first option for treatment of benign ampullary tumors, and it may be curative in selected cases of ampullary cancer confined to the mucosa. Endoscopic papillectomy compares favorably with surgical ampullectomy in terms of morbidity. However, it is not free of complications [19], and therefore, accurate staging is crucial to avoid a purposeless endoscopic resection. Up to now, EUS, alone or combined with IDUS, is the most performant technique for local staging of ampullary tumors. There are no accurate morphologic features to predict advanced stages other than ulceration of the papillary roof, which indicates submucosal invasion. Several authors advocate a cut-off size to allocate straight ampullary tumors to endoscopic resection without previous endosonographic staging. However, tumor size as a predictor of invasive stage is not a consistent criterion across the literature, and perhaps it may depend on other factors not well known at present, such as histologic features. Larger multicenter series are needed to investigate the interplay between tumor size and other tumor characteristics, confirm the specificity of intraductal invasion for malignancy, and gain more understanding about the biological behavior of the different subtypes of ampullary tumors. Meanwhile, EUS should always be performed when endoscopic resection is being considered as a therapeutic option, especially if we consider the limitations of endoscopic estimation of tumor size. Endosonographic staging is primarily focused on detecting submucosal infiltration and intraductal invasion. Whereas submucosal infiltration is an undisputable indication for surgery, the role of endoscopic resection in cases of limited intraductal invasion is still controversial. Further series will probably help to decide when surgery must be chosen instead of endoscopic ampullectomy.

\section{Competing interests: None.}

\section{References}

1 Horiguchi S, Kamisawa T. Major Duodenal Papilla and Its Normal Anatomy. Dig Surg 2010; 27: 90-93

2 Adsay NV, Bagci P, Tajiri T et al. Pathologic staging of pancreatic, ampullary, biliary, and gallbladder cancers: pitfalls and practical limitations of the current AJCC/UICC TNM staging system and opportunities for improvement. Sem Diagn Pathol 2012; 29: 127-141

3 Chen CH, Yang CC, Yeh YH et al. Reappraisal of endosonography of ampullary tumors: Correlation with transabdominal sonography, CT and MRI. J Clin Ultrasound 2008; 37: 18-25

4 Ridtitid W, Schmidt SE, Al-Haddad A et al. Performance characteristics of EUS for locoregional evaluation of ampullary lesions. Gastointest Endosc 2015; 81: 380-388

5 Ito K, Fujita N, Noda Y et al. Preoperative evaluation of ampullary neoplasm with EUS and transpapillary intraductal US: a prospective and histopathologically controlled study. Gastrointest Endosc 2007; 66: $740-747$

6 Chathadi KV, Khashad MA, Acosta RD et al. The role of endoscopy in ampullary and duodenal adenomas. Gastrointest Endosc 2015; 82: $773-781$

7 Baillie J. Endoscopic ampullectomy. Am J Gastroenterol 2005; 100: $2379-2381$ 
8 Patel $V$, Jowell $P$, Obando J et al. Does ampullary adenoma size predict invasion on EUS? Does invasion on EUS predict the presence of malignancy? Endosc Int Open 2016; 04: 1313-1318

9 Anderson BW, Smyrk TC, Anderson KS et al. Endoscopic overestimation of colorectal polyp size. Gastrointest Endosc 2015; 83: 201 - 208

10 Fennerty MB, Davidson J, Emerson SS et al. Are endoscopic measurements of colonic polyps reliable? Am J Gastroenterol 1993; 88: 496500

11 Woo SM, Ryu JK, Lee SH et al. Feasibility of endoscopic papillectomy in early stage ampulla of Vater cancer. J Gastroenterol Hepatol 2009; 24: $120-124$

12 Lee SY, Jang KT, Lee KT et al. Can endoscopic resection be applied for early stage ampulla of Vater cancer? Gastrointest Endosc 2006; 63: $783-788$

13 Yoon SM, Kim MH, Kim MJ et al. Focal early stage cáncer in ampullary adenoma: surgery or endoscopic papillectomy? Gastrointest Endosc 2007; 66: $701-707$

14 Aiura K, Hibi T, Fujisaki $H$ et al. Proposed indications for limited resection of early ampulla of Vater carcinoma: clinico-histopathological criteria to confirm cure. J Hepatobiliary Pancreat Sci 2012; 19: 707 716

15 Adsay $V$, Ohike $N$, Tajiri $T$ et al. Ampullary region carcinomas. Definition and site specific classification with delineation of four clinicopatholigically and prognostically distinct subsets in an analysis of 249 cases. Am J Surg Pathol 2012; 36: 1592 - 1608

16 Bohnacker S, Seitz $U$, Nguyen $D$ et al. Endoscopic resection of benign tumors of the duodenal papilla without and with intraductal growth. Gastrointest Endosc 2005; 62: 551-560

17 Merhendiratta $V$, Desilets $D J$. Use of radiofrequency ablation probe for eradication of residual adenoma after ampullectomy. Gastrointest Endosc 2015; 81: 1054-1055

18 Dzeletovic I, Topazian MD, Baron TH. Endoscopic balloon dilation to facilitate treatment of intraductal extension of ampullary adenomas (with video). Gastrointest Endosc 2012; 76: 1266 - 1269

19 Napoleon B, Gincul R, Ponchon T et al. Endoscopic papillectomy for early ampullary tumors: long-term results from a large multicenter prospective study. Endoscopy 2014; 46: 127-134 